\title{
Critical Success Factors in Hospitality ERP Models: Impact of IT Manager's Pro-activeness, Innovativeness and Rapport
}

\author{
Uday Kumar Adusumilli', Rajneesh Pandeya², Arvind Sebastian³ ${ }^{3}$, Dr. Nanda Ashwin ${ }^{4}$ \\ ${ }^{1}$ Product Support Analyst, Associate, Infor, Bangalore, Karnataka, India \\ ${ }^{2}$ Director, Infor, Bangalore, Karnataka, India \\ ${ }^{3}$ Manager, Infor, Bangalore, Karnataka, India \\ ${ }^{4}$ Professor, Department of Information Science and Engineering, East Point College of Engineering and \\ Technology, Bangalore, Karnataka, India
}

\begin{abstract}
In this paper, we examine the implications of Hospitality ERP (Enterprise Resource Planning) Systems, their Success Metrics, and what motivates people behind such systems. An analysis of the literature identifying and categorizing experimentally established critical success factors (CSFs) was conducted in order to accomplish this goal. Therefore, the result of the study is a proposal for a low-cost CSF implementation model. A crucial metric in that regard is innovation. Innovation can make or break a business model, and this is especially true in the Hospitality ERP Sector. Individuals' good ideas are at the core of innovations, so understanding how individuals and their personal characteristics contribute to innovation is crucial. We investigate how the values of employees have a direct influence on their innovative behavior in the current study as well. A worker's autonomy was hypothesized to mediate these relationships. Researchers found that values like openness to change and self-improvement values are positively correlated with job autonomy, whereas values like conservation and self-transcendence values are negatively correlated with it, which suggests that values play an important role in determining autonomy at work. A positive relationship between employees' selfenhancement values and their innovative behavior is also found, while a negative relationship appears to exist between conservation and self-transcendence values. Using a bias-corrected bootstrapping method, mediation analysis determined that job autonomy significantly mediates the relationship between employee personal values (except openness to change) and innovative behavior. Based on our research, we demonstrate that values provide the basis for innovative behavior. By showing the importance of job autonomy and personal values on inventive behavior in organizations, we also contribute to innovation research.
\end{abstract}

Keywords : ERP, ERP Implementation Success, Critical Success Factors, Critical Success Factors in Accounting, Systematic Literature Review Attitudes, Enterprise, Bias-Corrected Bootstrapping, Innovativeness, Innovative Behavior, It Managers, Personal Values. 


\section{INTRODUCTION}

Recent years have seen a rise in the number of practitioners and researchers who are concerned with the efficiency of ERP systems, in particular, when it comes to the critical success factors (CSF). In spite of multiple studies that identify these factors, a more concise or concise model of CSFs for ERP implementation success is needed. Creating such a model is what this paper attempts to do.

Product Analysts and Consultants should participate in the system analysis and design of any new ERP System, according to scholars in this area. Support Systems must be built from the ground up with controls integrated. This is one reason often given for this imperative. Similarly, implementation of ERP systems can also be viewed as a challenge. In order to achieve the objectives of the research paper, it intends to provide Product Analysts and Consultants with an understanding of the factors critical to the successful implementation of ERP systems, as well as how to identify whether the implementation was successful. In order to influence managers' behavior towards innovation, values have been found to play an important role. Keeping up with competition in an international environment requires continually modifying the way enterprises work and behave, especially in terms of their management strategies, in order to survive. In literature, innovation is any aspect of an idea that is deemed to be beneficial to its users, thus improving their experience. Innovation is not only the ability to create something new, but also the ability to commercialize that creation. There is a substantial body of literature devoted to the study of modern business and how it can be achieved; innovation is also treated separately in the literature. It is well known that management literature contains a lot of references to innovations, business, and quality, but they are largely discussed separately from innovative behavior.

It is important for managers to know how to behave in order to be able to make informed decisions. Most of the factors that relate to their behavioral patterns have been neglected in modern business. As mentioned earlier, values, culture, ethics, norms (VCEN), subjective resources, and the spiritual side of things) together with objective resources are the basis on which managers form their attitudes towards innovation. Considering the definition of innovativeness, it can be defined as the ability, willingness, or capacity of an organization to implement new ventures or innovations based upon novelties or inventions. In recent years, IT industry professionals have begun to value creativity more. A high level of analytical, innovative, and creative ability is expected of IT managers in organizations, based upon the behaviors that they possess. Within that framework, there are important issues to consider regarding innovation and what is driving innovation. In regard to all the factors that contribute to innovativeness, the internal factors, which explain how managers' behavior is correlated with their innovation, receive the least attention.

The relationship between managers' personal values and their innovativeness hasn't been considered holistically in the literature, according to a review of relevant literature. In addition, managers in IT departments are using soft factors to determine their behavior that is in contrast to all the hard and technical criteria. According to that framework, the main soft driver, namely personal values, is not directly related to innovativeness for IT managers in organizations. Specifically, this study investigates the relationship between information technology managers' personal values and their innovation capability at all degree levels of their values - as well as at the level of single values, as well as those within the widest range of managers' values. Several studies have shown a positive relationship between IT managers' values and their ability to innovate.

By connecting the existing theoretical research on the impact of managers' values on their ability to innovate and the limited empirical evidence about theoretical cognitions about the selected problem, this 
study reduces the gap between the well-established theoretical research. As well as enhancing the existing literature, this research adds to it by expanding upon and upgrading the mostly partial discussions about management behaviors, values, and innovativeness by investigating the relationship between managers' personal values and attitudes towards innovation. Additionally, this paper clarifies the relationship between IT managers' personal values and their innovativeness in a way that has not previously been explored in the literature. This paper also contributes to understanding the role and importance of managers' personal values as an important factor in their ability to innovate.

To add to management research investigating organizational variables, it is especially crucial to understand the psychological mechanisms conducive to Managers' innovation. Research to further understand individual innovation in organizations is needed, according to a recent book review by Anderson et al. (2018). Organizational innovation relies heavily on the behavior of managers, as they are responsible for developing and implementing innovative solutions. It is essential to study individual values in order to examine how they contribute to innovation by employees (Schwartz, 1992). As postulated by philosophy, values are important drivers of actions in organizations. These associations are, however, hardly studied empirically.

\section{CRITICAL SUCCESS FACTORS}

This study aims to analyze a selection of empirical studies that deal with the implementation of ERP systems. Academic studies provide evidence that certain components contribute to the success of ERP implementation. Figure 1 shows the final model, which takes into account the majority of factors found in the review literature. Using the characteristics of the factors examined in these studies, a grouping has been done. Factors that influence the success of an ERP implementation are: the characteristics of the environment (the cultural and structural characteristics of the environment), the ERP software characteristics, the characteristics of the implementation team, the characteristics of top management, the characteristics of the implementation process, as well as those of end users.

\section{a) Factors culturally relevant to the environment}

Environments are affected by a variety of factors, such as culture and structure. I would like to introduce some factors which are specific to corporate culture and that will be discussed in this section. There is also a structural aspect of the environment, which is discussed in the following chapter, which relates to factors in the environment that do not necessarily relate to corporate cultures, but rather to the company's particular industry or market environment.

In the context of environment/culture, critical success factors (CSF) include cultural acceptance, readiness of the environment/culture, open and honest communication, and the willingness to accept challenge. According to Krumbholz and colleagues' (2000) findings, different aspects of training and the systems within organizations can be attributed to cultural importance. Among the CSFs identified in this study, and perhaps others, as part of the study examining the effect of different national cultures and organizational cultures on successful ERP implementations, are those listed below.

A critical success factor of ERP implementations is the need to overcome resistance to change. Studies have shown that this factor is influential in the success of ERP implementations and several studies have examined this topic. As a result of resistance to change within organizations, there is a natural inertia that results. The researchers Duplaga \& Astani (2003) had survey respondents weigh in on the issue of change resistance as a key obstacle to successful implementation.

Using organizational resistance as a moderator between successful ERP implementation and 
resistance to change, Hong and Kim (2002) found organizational fit to be instrumental to the success of ERP implementation. In particular, they felt that organizational resistance was caused by uncertainty about the new system and the new jobs, as well as other reasons that are related to change in the workplace. In Hong and Kim's (2002) study, they identified resistance to change as one of the primary factors impeding the success of ERP implementation.

CSF was related to open, honest communication, according to two studies. In many cases, openness and honest communication of managers and employees are regarded as desirable characteristics in corporate cultures where interpersonal trust prevails (Nah et al., 2003; and Sarker and Lee, 2003). Sarker and Lee (2003) identified the importance of open, honest communication as one of the key enabling factors for an ERP implementation to succeed. As a generality, it means that all levels of a project's management with the users are communicating openly and honestly with one another.

\section{b) Environments from a structural perspective}

In several studies, structural factors were identified. ERP implementations are often motivated by competitive pressure in some industries. (Bradford and Florin, 2003) This factor is a critical contributor to successful implementation since it keeps organizations motivated throughout the process.

Many studies identified employee turnover, insufficient IT personnel, and a lack of business knowledge within organizations as risk factors. These indicators indicate general tightness in the labour market, and they are particularly concerning in some environments. ERP implementation requires proper personnel, but is challenging without them.

\section{c) Software characteristics}

In order to implement software successfully, it must have certain characteristics. Software packages should be carefully compared to the company's specific needs before adoption. While a few vendors dominate sales of ERP systems, there are actually a wide variety of vendors. Depending on the software product that is used, different effects can be experienced on the ERP implementation.

Several studies identified software complexity as a major concern. The complexity of ERP software hinders users and implementers from understanding and implementing it in the business processes of an organization. Additionally, the more complicated the software is, the bigger the cost and time it will take to implement. A complex software system may not be conducive to a successful implementation of ERP.

Compliance with local legislation is a crucial success factor when implementing ERP software internationally. Whether the software is efficiencyoriented or flexible-oriented affects how the organization handles possible business process changes, and accordingly the success of implementation. It is important to assess whether the assumptions and business rules used in an ERP implementation are appropriate for the company and industry in order to determine whether the implementation will be successful.

\section{d) Features of the firm}

There has been no literature review that discusses the characteristics of the end users, the implementation team, and the management, but we would like to point out that one other CSF has been identified. Researchers have recognized that firm size is a key factor that determines the success or failure of ERP implementations. The size of the firm was used as the control variable in the study by Manbert et al., 2000. A typical way of conducting this kind of study would be to use an independent variable or characteristic that has a significant impact on the dependent variable, but one that isn't crucial to the analysis.

There was no significant effect on the results. Astani (2003) found that firm size moderated the relationship between ERP implementation success and various independent variables. Firm size was the only independent variable used by Mabert et al. 
(2000), which found its impact to be significant on success variables.

\section{e) Characteristics of successful implementation teams}

In some studies, experienced consultants have been employed as part of successful implementation processes. Consultants are important since they bring both knowledge and experience in implementation. Implementation success factors such as these are rarely present in ERP implementations.

There were observations made that not all consultants were experienced, so they needed to differentiate between those who were inexperienced and those who were experienced. In reply to questions, Executives at the company replied that as much as the consultants learned from the company, the company learned from them. In spite of this, consulting usually helps companies solve their problems, and that's why consultants are considered highly valuable.

\section{f) Role and characteristics of top management}

Setting clear objectives and defining clear goals is a crucial aspect of ensuring the success of an ERP project. According to an old adage, if you do not know in which direction you are headed, you will not be able to get anywhere. It is essential to have clear objectives and goals in order to resolve the conflict in the most satisfactory manner. Establishing goals and objectives requires top management support, involvement, and participation in order to be successful.

Despite being involved and participating in ERP implementations, Umble et al. report that both these aspects were important to ensuring success. Executive participation is when the CEO participates directly in the management of the organization's IT. Information technology is viewed as highly important by the CEO based on their involvement. An ERP implementation's success was significantly influenced by the age and functional background of top management executives.

\section{g) Implementation characteristics}

In the implementation of ERP systems, one of the primary conflicts is the choice between changing the software or developing business processes. As ERP software is available "off-the-shelf" and business processes are not uniform across industries, this conflict causes the implementation of ERP to have varying degrees of each for each customer. As a result of business process engineering, the firm's operations are changed to conform to the rules imposed by software.

It may be necessary to modify the software where this is neither desirable nor possible. The problems associated with each are unique to them. Whenever resistance to change is present, business process engineering becomes problematic. When new versions of software are released, software modifications lead to upgrading issues. These factors were analyzed in a number of studies.

\section{h) End-users characteristics}

As a final point, in some studies, characteristics of end users have been shown to predict ERP implementation success based on adoption, use, and satisfaction. (Sumner, 2000) found that end-user attitudes toward ERP systems impacted the outcome of implementations.

Abdinnour-Helm et al. (2003) examined user involvement in the ERP implementation process. The study by Abdinnour-Helm et al. (2003) found that employees in management positions and those with the shortest tenure were more likely to be satisfied. 


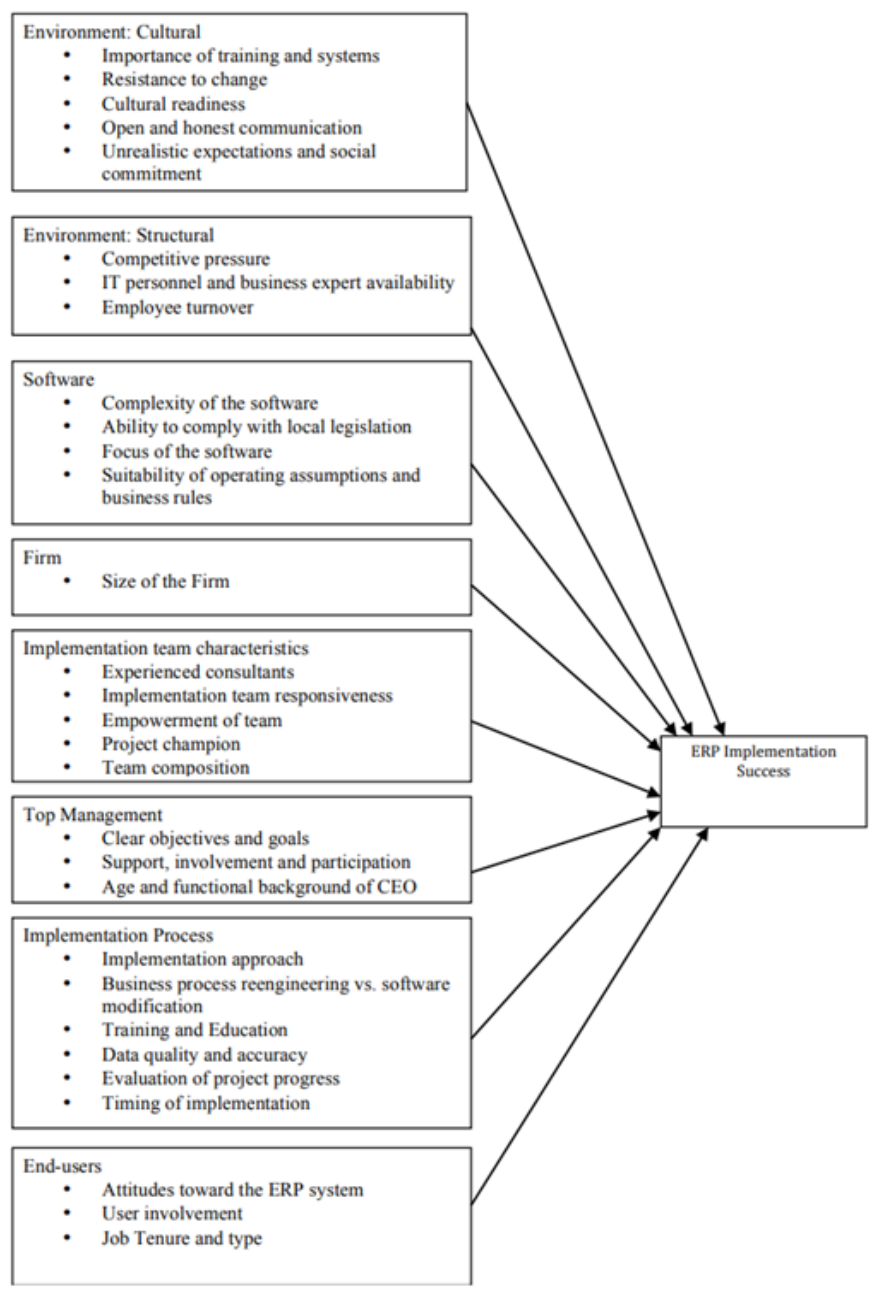

Figure 1. An Analysis of ERP Implementation Success

\section{RELATIONSHIP BETWEEN EMPLOYEE VALUES AND INNOVATION}

Schwartz's theory of basic human values (developed in 1992) constitutes the most comprehensive and empirically based theory of human values. In her 1994 publication, Schwartz defined values as "desirable transsituational goals of varying importance, which guide the decisions made by individuals or other entities in their daily lives" (Schwartz, 1994, p. 21). As individuals and in social contexts, we find ourselves motivated to take action by our personal values, which give us direction and provide emotional intensity (Schwartz, 1994). According to this theory, basic values are organized according to their underlying motives and form a universal, circular continuum. A motivation's relationship with another may be complementary, conflictual, or irrelevant. In order to partition the value continuum, it has a structured nature (Roccas, 2017). In the initial description of ten basic values, two bipolar dimensions can be distinguished: (1) openness to change (self-direction and stimulation) versus conservation (tradition, conformity, and security) and (2) self-transcendence (universalism and benevolence) versus self-enhancement (power and achievement); hedonism values share aspects of both dimensions.

Researchers apply this concept frequently in their studies to distinguish between four highly valued higher-order values (which are openness to change, conservation, self-enhancement, and selftranscendence) and will apply this method in our study.

A higher-order evaluation of openness to change is one that includes factors like self-direction and stimulation, which are also factors of openness to change. I believe that openness to change is defined in terms of the willingness to choose, the ability to create, and the ability to explore, as well as the preference for novelty and change as motivational goals. Self-direction has been cited as one of the most important qualities for creativity based on two factors: self-control and self-awareness.

As part of the concept of self-direction Schwartz (1992) recognized that creativity is a valuable tool. It is also important to keep in mind that independent thought and action is a prerequisite for self-direction, which can be reflected in exploring and following one's own interests, which is also considered crucial for creative individuals. Self-directed individuals prefer independent thinking as well as independent action, which is conducive both to generating creative ideas and implementing innovations. To achieve stimulation, Schwartz suggests that one seeks new experiences, excitement, and challenges in life. Furthermore, stimulation is also believed to contribute to the promotion of innovation in order to achieve these goals. In conclusion, we can infer that openness to change values is among all of the higher- 
order values in relation to innovative behavior to be the most favourable one. Due to their motivational meanings, openness to change values has been associated with creative and innovative thinking, as confirmed by previous empirical research that has tested the hypothesis. As Kasof et al. (2007) found, individual creativity is positively related to both selfdirection and stimulation. Openness to value change is also a positive predictor of creativity (Dollinger et al., 2007). According to Sousa and Coelho (2011), employees who are open to change are less likely to be creative, and self-directed employees are more likely to be creative too (Rice, 2006). Schwartz's (1992) theory says that we can expect employees to be willing to act innovatively when they value novelty, experimentation, and exploration (which are typically values of people who are open to change). Our hypothesis was developed based on these theoretical assumptions and previous research findings.

\section{Hypothesis 1a. Employees' willingness to change values correlates positively with their innovative behavior.}

In contrast, conservation values, such as conformity, security, and tradition (Schwartz, 1992), appear to negatively affect employees' ability to innovate. In the face of such values, an individual adopts customary behavior and established procedures that are undoubtedly detrimental to innovative thinking (Sousa et al., 2012). Employees who attribute a high value to conformity may disregard innovative initiatives because they may produce changes that are not readily recognized by their peers (Schwartz, 1992) because conformity is designed to prevent upsetting or violating social norms.

According to Kasof et al. (2007), all three components of conservation - tradition, conformity, and security negatively affect creative performance. Consequently, an employee who is unwilling to introduce novelty and rejects alternate methods and new perspectives (which is common among conservationists) is unlikely to display innovative behavior (facilitating design, implementation and promotion of ideas) because it could potentially disrupt the status quo. Therefore, we developed the following hypothesis.

\section{Hypothesis $1 \mathrm{~b}$. Innovation behavior is negatively related to employees' conservation values.}

Power and achievement (Schwartz, 1992) are reflected in self-enhancement values, which revolve around social esteem. Having power is gaining prestige, attaining social status, and controlling or dominating others. The implementation of innovative ideas in the workplace can be a potential method for achieving these goals because managers who are striving for innovative performance will acknowledge employees who behave in a forward thinking manner (Janssen et al., 2004). Innovative behavior can also enable an employee to obtain social prestige in a company and perform well in the company's hierarchy. Additionally, personal success is the central goal of Value of Achievement, and is achieved through demonstration of competence to meet social standards (Schwartz, 1992).

These results seem to be in agreement with the view that strong achievement orientations are possessed by creative people (Mumford, 2000; Sousa and Coelho, 2011), as well as the view that power motivation is significant for creative personalities (Helson, 1996). When people promote and implement their creative ideas, they may achieve goals related to power and achievement values. Activities like these can help employees gain prestige, be perceived as successful by co-workers and supervisors, and increase their organizational status. As a result, we believe employees who regard self-enhancement values highly will be more apt to behave in an innovative manner.

\section{Hypothesis 1c. Innovation behavior is positively} correlated with employees' self-enhancement values.

Universalism and benevolence are traits associated with self-transcendence (Schwartz, 1992). Arieli and Tenne-Gazit (2017) believe that it is in the 
individual's nature to establish relationships with other people. Values, as the most abstract, seem the least related to work context (Sousa et al., 2012). Yet there is empirical evidence that they have a connection to creativity. Among college students, universalism is positively correlated with creativity, according to Gump (2007).

\section{EMPLOYEES' INDIVIDUAL VALUES AND THEIR AUTONOMY IN RELATION TO EACH OTHER}

Peoples' attitudes, judgments, and actions are affected by their personal values (Feather, 1988) and serve as a guide for them in their actions, decisions, and perceptions (Schwartz, 1994). Consequently, employees' autonomy is a factor affecting values. We argue that people are predisposed to actively seek autonomy in their work if they share a certain set of values, while others may not undertake that endeavor. There are various kinds of autonomy that people experience in work and organizational settings (Morgeson and Humphrey, 2006). Using this technique can result in positive work outcomes, such as innovation (De Spiegelaere et al., 2014), employment satisfaction, internal work motivation (Humphrey et al., 2007) and work engagement (Bamberger, 2010). In most of these studies, autonomy is conceptualized in accordance with Hackman's (1976) job characteristics, which define autonomy as the degree of freedom and independence offered by a job. Throughout the organization, decisions, work assignments, and procedures can be made freely.

In addition to openness to change values, Gorgievski et al. (2017) found that entrepreneurial intentions are more closely linked to artistic and investigative careers (Sagiv, 2002; Knafo and Sagiv, 2004). We expect that an employee's importance of openness to changing values is positively related to their autonomy at work based on these theoretical and empirical premises.
Hypothesis 2a. The degree of autonomy employed by employees is positively correlated with their openness to change values.

Conservatism includes the values of conformity, security, and tradition, which are in opposition to the values of adaptability and openness. Self-restraint is a major component of conformity values, which is reflected in everyday interactions with close others, such as self-restraint of actions, impulses, and inclinations (Schwartz, 1992).

In our experience, people who place a great deal of importance on conservation values are seldom interested in enhancing their level of job autonomy because this is not congruent with their beliefs, since their professional choices impact how they engage in professional behavior. As a result, we developed the following hypothesis.

\section{Hypothesis $2 \mathrm{~b}$. The job autonomy of employees is} negatively related to their conservation values.

In addition to power and achievement, selfenhancement is characterized by higher-order values (Schwartz, 1992). The pursuit of power involves achieving prestige, social status, dominance, and control over people and resources. Attributing value to achievement involves demonstrating competence, which is a way to show that the achievement has been accomplished.

Career counselling client achievement values were related to independence, and greater awareness of oneself was related to entrepreneurial career intentions among students with different countries of origin. In light of these premises, the selfenhancement values of employees should be positively correlated with employee autonomy.

\section{Hypothesis 2c. An employee's level of autonomy is} positively related to their self-improvement values.

In addition to universalism and benevolence, selftranscendence involves benevolence. According to Schwartz (1992), universalism is concerned with the welfare of all people and nature as well. Beneficial 
motivation involves concern for close relatives, and this concern is expressed through daily interactions.

However, neither theoretical nor empirical evidence suggests that employee self-transcendence and autonomy are directly related.

\section{AUTONOMY AND INNOVATION IN THE WORKPLACE}

Several studies have shown that job autonomy and innovation are contextual preconditions to each other. Meta-analysis conducted by Hammond et al. (2011) found that among all predictors evaluated in their study, job autonomy was the strongest predictor of creativity and innovation.

The relationship between autonomy and creativity and innovation has been well studied. It has been observed that job autonomy positively affects employees' innovative behavior at work and job creativity (Liu, 2011, 2013). We propose that job autonomy positively correlates with employees' innovative behavior, based on the job characteristics theory (Hackman and Oldham, 1980) as well as the self-determination theory, which emphasizes the role of job autonomy in motivating employees to innovate.

\section{Hypothesis 3. A positive relationship exists between} employee autonomy and innovative behavior.

\section{MEDIATING BETWEEN INDIVIDUAL VALUES AND INNOVATION: THE ROLE OF THE JOB AUTONOMY}

Several studies have examined the importance of values in predicting creative and innovative behaviors but how they work is still unclear (Sousa and Coelho, 2011). For example, in a study conducted by Choi (2003), no evidence was provided to confirm a relationship between innovation-use behavior and innovative organizational culture. To understand individual innovation, we must investigate other mechanisms. As a result, we postulate indirect relationships between employee values and their innovation behavior, as well as suggest that job autonomy can mediate these relationships (Figure 2).

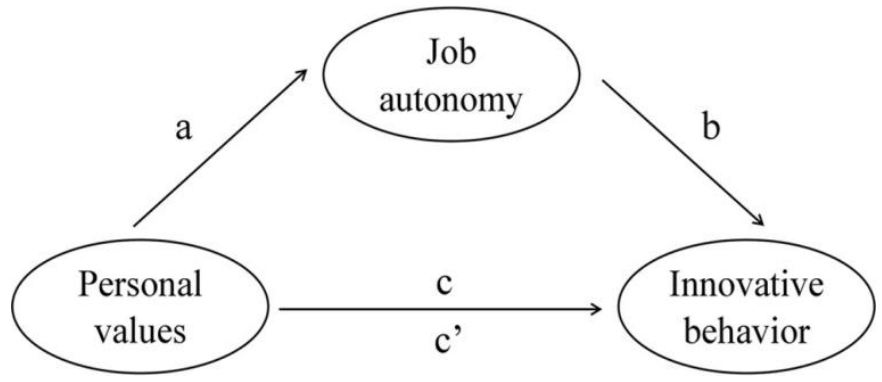

Figure 2. This diagram illustrates how the relationships are conceptualized in the study.

The relationship between personal values and work outcomes has been viewed in some previous studies as mediated by job autonomy rather than a moderator of this relationship (Coelho, 2013). To test whether job autonomy can play a mediating role, we propose to go beyond this pattern. In order to test whether job autonomy mediates the link between employees' values and innovation, we propose a study.

Hypothesis 4. The autonomy of employees impacts their openness to change (H4a), conservation (H4b), self-enhancement $(\mathrm{H} 4 \mathrm{c})$, and transcendence (H4d) values, as well as innovative behavior.

\section{VII.METHODOLOGY AND PARTICIPANTS}

A survey was conducted with employees from micro-, small-, and medium-sized enterprises operating in Poland that employ 1-250 people. The study excluded employees working for bigger companies and corporations as their work may be governed by more restrictive policies (Frant, 1993). We collected the data by contacting the participants directly and asking them questions on paper and pencil. The participants in the study participated voluntarily and received no reward. The information was kept confidential and anonymous.

Two hundred and sixty-three employees (including 138 women) took part in this study. From 19 to 74 
years old, they ranged in age from 33.88 to $10.62(\mathrm{M}=$ 33.88, $\mathrm{SD}=10.62)$. As for work contracts, 155 participants (55.6\%) were employed under a full-time permanent contract, $49(18.1 \%)$ under a temporary contract, and 59 (25.7\%) under another type of contract. There were $44.1 \%$ of respondents with a graduate degree, $10.3 \%$ with a bachelor's degree, $34.6 \%$ with a high school diploma and only $8.7 \%$ with a vocational diploma; six participants $(2.3 \%)$ failed to provide information. Overall work tenure for participants was between 2 months and 46 years $(\mathrm{M}=$ 11.43 years, $\mathrm{SD}=10.22$ ). They have lasted between 1 month and 32 years at their current company $(\mathrm{M}=$ 5.63 years, $\mathrm{SD}=6.51$ ). They were employed by companies with an average of 56 employees $(\mathrm{M}=$ 54.94, $\mathrm{SD}=61.73, \mathrm{Me}=20.00$ ). The participants were classified according to the 2012 edition of the International Standard Classification of Occupations (ISCO-08): Professionals (36.7\%); artisans (19.8\%); service workers (18.3\%); technicians and associate professions (13.7\%); clerks (4.9\%); manufacturers (3\%); and elementary occupations (1.9\%).

\section{MEASURES AND METRICS}

\section{a) Personal Values}

The 21-item Questionnaire was used to measure the values of the employees (Schwartz, 2003a). Among the items on his list are: He values creativity and generating new ideas. It is important to him to show his skills in his own original way; he likes to do things in his own way. What he does, he wants people to admire. Participants were asked, "How similar is this individual to you?" and scored on a 6-point scale ranging from $1=$ very similar to me to $6=$ not at all similar to me. Participants' responses were recorded to associate a higher score with a higher value. Raw scores were cantered by computing each individual's mean score across all 21 items (i.e., the MRAT), and corrected scores were calculated by subtracting the MRAT from the individual's mean score for each item. We evaluated the internal consistency of the scale using Cronbach's alpha. Cronbach's alpha values were 0.56 for openness to change, 0.67 for conservation, 0.68 for self-enhancing, and 0.72 for self-transcending. As a result of the characteristics of the questionnaire, such low levels of reliability are typical. It was verified using confirmatory factor analysis (CFA) that the measure was factorial. Having a CFI (confirmatory factor index) value of 0.90 or greater indicates an acceptable model fit. For the MRAT indices, a value below 0.05 indicates good model fit, and a value below 0.08 (and up to) indicates an acceptable fit;

\section{b) Job Autonomy}

Work Design Questionnaire (Morgeson and Humphrey, 2006) measured the autonomy experienced by employees at work using four items of the autonomy scale. In the scale, each item is a statement (e.g., My job gives me the opportunity to use my own initiative and judgment when carrying out my work), to which the participants should respond using a five-point answer scale ranging from 1 = strongly disagree to 5 = strongly agree. The reliability of the autonomy scale was very good, as indicated by Cronbach's alpha of 0.90 in the present study. Our CFA showed good fit to the data with the one-factor model $(\mathrm{CFI}=1.00)$.

\section{c) Innovative Behavior}

Scott and Bruce (1994) administered the Innovative Behavior Questionnaire to measure participants' innovation behaviors. There are six items in the questionnaire (e.g., I develop creative ideas; I develop adequate plans to implement new ideas). Participants were asked to rate how often they behaved as described in each statement, using a five-point scale ranging from 1 = never to 5 = very often. Scale reliability in the present study was 0.85 , indicating sound internal consistency. Purc and Laguna (2017) recommended the CFA, which confirmed the measure's one-factor structure. This analysis showed that a model of this type fits data well $(\mathrm{CFI}=0.998)$. 


\section{RESULTS}

All paragraphs must be indented. All paragraphs must

a) Correlations between the study variables and descriptive statistics

A description of the study and Pearson's correlations are presented in Table 1. Based on personal values, there are significant correlations between the bilateral dimensions, suggesting their opposite positions on the motivating values continuum, as outlined in Schwartz's (1992) values theory. Openness to change values were negatively correlated with conservation $(\mathrm{r}=-0.69, \mathrm{p}<0.001)$, and self-enhancement values were negatively correlated with self-transcendence values $(\mathrm{r}=-0.54, \mathrm{p}<0.001)$.

\begin{tabular}{|c|c|c|c|c|c|c|c|c|}
\hline & Variables & M & So & 1 & 2 & 3 & 4 & 5 \\
\hline 1 & Opeemess to change & -0.02 & 0.67 & & & & & \\
\hline 2 & Consenation & 0.09 & 0.61 & $-0.69^{* * *}$ & & & & \\
\hline 3 & Selt erhancement & -0.42 & 0.69 & 0.10 & $-0.48^{m *}$ & & & \\
\hline 4 & Selt-transcendence & 0.51 & 0.59 & $-0.28^{\prime *}$ & 0.12 & $-0.54 \cdots$ & & \\
\hline 5 & Autonomy & 3.37 & 0.99 & $0.12^{\circ}$ & $-0.14^{\circ}$ & $0.21 "$ & $-0.20 "$ & \\
\hline 6 & Imovative behavior & 3.33 & 0.76 & 0.08 & $-0.22^{\cdots}$ & $0.255^{\prime \prime \prime}$ & -0.09 & $0.49^{* \prime}$ \\
\hline
\end{tabular}

Table 1. Correlations between study variables, means, and standard deviations $(\mathrm{N}=263)$.

\section{b) Hypotheses Testing}

Using the PROCESS macro (Model 4, Hayes, 2013), mediation analyses were conducted. This bootstrapped sample was used to estimate both direct and indirect effects. In Table 2, we report the bootstrapped standard error (SEB) and 95 percent confidence intervals (CIs) for each of the direct effects ( $a, b$, and $c$, as shown in Figure 1), as well as the indirect effect (c).

\begin{tabular}{|c|c|c|c|c|c|c|}
\hline \multirow{2}{*}{ Predictor } & \multicolumn{3}{|c|}{ Direct effects } & \multirow[b]{2}{*}{$c^{\prime}$} & \multicolumn{2}{|c|}{ Indirect effect } \\
\hline & a & b & c & & SEB & $95 \% \mathrm{Cl}$ \\
\hline Openness to change & $0.18^{\circ}$ & $0.37 \cdots$ & 0.08 & 0.07 & 0.04 & $-0.01,0.16$ \\
\hline Consenation & $-0.22^{\circ}$ & $0.36^{\circ}$ & $-0.20^{* *}$ & -0.08 & 0.04 & $-0.17,-0.01$ \\
\hline Selt-enhancement & $0.30 \cdots$ & $0.35 \cdots$ & $0.17^{*}$ & 0.10 & 0.03 & $0.04,0.18$ \\
\hline Selt-transoendence & $-0.33^{*}$ & $0.38^{\cdots} \cdot$ & 0.002 & -0.13 & 0.04 & $-0.21,-0.05$ \\
\hline
\end{tabular}

Table 2. Mediation analysis results.

Our first concern was verifying hypotheses $\mathrm{H} 1 \mathrm{a}-\mathrm{H} 1 \mathrm{c}$ based on direct effects. Based on the analysis, two of the four higher-order values were associated with innovation. There was no significant correlation between employee openness to change values and innovative behavior $(\mathrm{B}=0.08, \mathrm{SEB}=0.06, \mathrm{p}=0.187$ ). As a result, we reject hypothesis H1a. The conservation values significantly influenced innovative behavior $(B=0.20, \mathrm{SEB}=0.07, \mathrm{p}=0.004$ ), supporting hypothesis $\mathrm{H} 1 \mathrm{~b}$. Innovative behavior was also proven to be directly related to self-enhancement values. It was expected that the higher the value employees placed on self-improvement, the more innovative their behavior would be $(\mathrm{B}=0.17, \mathrm{SEB}=$ $0.06, \mathrm{p}=0.005)$. Hence, hypothesis H1c holds true. There was no statistically significant relationship between self-transcendence values and innovative behavior ( $\mathrm{B}=0.002, \mathrm{SEB}=0.07, \mathrm{p}=0.973)$. The hypotheses $\mathrm{H} 2 \mathrm{a}-\mathrm{H} 2 \mathrm{c}$ suggest that an employee's personal values affect their job autonomy. There were statistically significant relationships between all four higher-order values and employee job autonomy. In this study, openness to change values has been found to predict autonomy ( $\mathrm{B}=0.18, \mathrm{SEB}=0.09, \mathrm{p}=0.046$ ), allowing hypothesis $\mathrm{H} 2 \mathrm{a}$ to be accepted. In agreement with hypothesis $\mathrm{H} 2 \mathrm{~b}$, conservation values are negatively related to employee perceptions of job autonomy $\left(\mathrm{B}={ }^{*} 0.24\right.$, SEB $\left.=0.10, \mathrm{p}=0.024\right)$. Selfenhancement values were also shown to be a significant predictor of job autonomy, and this effect was positive $(B=0.30, \mathrm{SEB}=0.09, \mathrm{p}<0.001)$. The results indicate that hypothesis $\mathrm{H} 2 \mathrm{c}$ is supported. Employees with higher levels of self-transcendence had lower levels of job autonomy $\left(\mathrm{B}={ }^{*} 0.33\right.$; $\mathrm{SEB}=$ $0.10, p=0.001$ ). Based on our findings, we infer that employee self-transcendence values negatively influence the level of job autonomy.

In Hypothesis H3, job autonomy and innovation behavior were analyzed for their potential positive relationship. In order to test this hypothesis, we examine whether there is a direct relationship between autonomy and innovative behavior; job autonomy was a significant predictor of innovative behavior, and this relationship was strong in all four equations, including different personal values (for 
openness to change, $\mathrm{B}=0.37$, $\mathrm{SEB}=0.04, \mathrm{p}<0.001$; for conservation, $B=0.36, S E B=0.04, p<0.001$; for self-enhancement, $B=0.35, \mathrm{SEB}=0.04, \mathrm{p}<0.001$; and for self-transcendence, $B=0.38, \mathrm{SEB}=0.04, \mathrm{p}<0.001$ ). In order to verify hypotheses $\mathrm{H} 4 \mathrm{a}-\mathrm{H} 4 \mathrm{~d}$, indirect bootstrapped effects were analyzed. According to hypothesis $\mathrm{H} 4 \mathrm{a}$, openness to change values and innovation are related through the notion of job autonomy. Due to $95 \% \mathrm{CI}$ including zero, the indirect effect was nonsignificant $(B=0.07, \mathrm{SEB}=0.04,95 \%$ CI $\left.\left[{ }^{*} 0.01,0.16\right]\right)$. Hypothesis $\mathrm{H} 4 \mathrm{a}$, therefore, is rejected. Job autonomy has been found to influence the relationship between conservation values and innovative behavior in a significant manner $\left(B={ }^{*} 0.08\right.$, $\mathrm{SEB}=0.04,95 \%$ CI $\left.\left[{ }^{*} 0.17,{ }^{*} 0.01\right]\right)$, thus supporting hypothesis H4b. Additionally, Hypothesis $\mathrm{H} 4 \mathrm{c}$ is supported - the relationship between selfenhancement values and innovative behavior was significantly mediated by job autonomy $(\mathrm{B}=0.10$, $\mathrm{SEB}=0.03,95 \%$ CI $[0.04,0.18])$. The relationship between self-transcendence values and innovative behavior was also influenced by job autonomy ( $\mathrm{B}=$ -0.13 , SEB $=0.04,95 \%$ CI $[-0.21,-0.05])$. The results of this experiment confirm hypothesis $\mathrm{H} 4 \mathrm{~d}$ as well. As a result, three of the four specific mediation hypotheses have been confirmed. It can be concluded that work autonomy is a significant mediator of the relationship between employees' innovative behavior and their personal values (e.g., conservation, selfenhancement, and transcendence).

Our first concern was verifying hypotheses $\mathrm{H} 1 \mathrm{a}-\mathrm{H} 1 \mathrm{c}$ based on direct effects. Based on the analysis, two of the four higher-order values were associated with innovation. There was no significant correlation between employee openness to change values and innovative behavior $(\mathrm{B}=0.08, \mathrm{SEB}=0.06, \mathrm{p}=0.187$ ). So, hypotheses $\mathrm{H} 1 \mathrm{a}$ and $\mathrm{H} 2 \mathrm{a}$ are rejected. This hypothesis is supported by conservation values showing a significant negative effect on innovative behavior ( $\mathrm{B}=0.20, \mathrm{SEB}=0.07, \mathrm{p}=0.004$ ). Innovative behavior was also proven to be directly related to selfenhancement values. It was expected that the higher the value employees placed on self-improvement, the more innovative their behavior would be $(B=0.17$, $\mathrm{SEB}=0.06, \mathrm{p}=0.005)$. The H1c hypothesis is thus supported. No statistically significant effect was observed between self-transcendence values and innovative behaviors $(\mathrm{B}=0.002, \mathrm{SEB}=0.07, \mathrm{p}=$ 0.973).

Based on hypotheses H2a and H2c, employee autonomy may be affected by personal values.

The relationship between job autonomy and higherorder values was statistically significant for each of those values. This hypothesis was accepted on the basis of an association between change in values and autonomy ( $\mathrm{B}=0.18, \mathrm{SEB}=0.09, \mathrm{p}=0.046$ ). The employee's perception of job autonomy is negatively correlated with a company's conservation values $(\mathrm{B}=$ $-0.24, \mathrm{SEB}=0.010, \mathrm{p}=0.024)$. Further, the presence of self-enhancement values was found to predict job autonomy, with a positive result $(B=0.30, S E B=0.09$, p0.001). Based on these results, hypothesis $\mathrm{H} 2 \mathrm{c}$ is supported. The level of self-transcendence of employees was associated with a lower level of job autonomy $(\mathrm{B}=-0.19 ; \mathrm{SEB}=0.10, \mathrm{p}=0.001)$. In conclusion, self-transcendence values and employee job autonomy are negatively related in this study.

An analysis of the potential positive relationship between job autonomy and innovation behavior was conducted in Hypothesis H3. A direct effect of autonomy on innovation behavior supports this hypothesis; job autonomy was a significant predictor of innovation behavior, and the relationship was positive for each of the four equations, regardless of personal values (for openness to change, $\mathrm{B}=0.37$, $\mathrm{SEB}$ $=0.04, \mathrm{p}<0.001$; for conservation, $\mathrm{B}=0.36, \mathrm{SEB}=$ $0.04, \mathrm{p}<0.001$; for self-enhancement, $\mathrm{B}=0.35, \mathrm{SEB}=$ $0.04, \mathrm{p}<0.001$; and for self-transcendence, $\mathrm{B}=0.38$, $\mathrm{SEB}=0.04, \mathrm{p}<0.001$ ).

A bootstrapped analysis of indirect effects was conducted to verify hypotheses $\mathrm{H} 4 \mathrm{a}-\mathrm{H} 4 \mathrm{~d}$. According to hypothesis $\mathrm{H} 4 \mathrm{a}$, openness to change values and innovation are related through the notion of job autonomy. Due to the fact that the $95 \%$ confidence 
interval includes zero, the indirect effect was not significant ( $\mathrm{B}=0.07, \mathrm{SEB}=0.04,95 \% \mathrm{CI}\left[{ }^{*} 0.01,0.16\right]$ ). The hypothesis $\mathrm{H} 4 \mathrm{a}$ is therefore rejected. Job autonomy has been found to influence the relationship between conservation values and innovative behavior in a significant manner $\left(B={ }^{*} 0.08\right.$, $\mathrm{SEB}=0.04,95 \%$ CI $\left.\left[{ }^{*} 0.17,{ }^{*} 0.01\right]\right)$, thus supporting hypothesis $\mathrm{H} 4 \mathrm{~b}$.

In terms of hypothesis $\mathrm{H} 4 \mathrm{c}$, job autonomy was found to be significantly influential in determining the relationship between self-enhancement values and innovative behavior $(\mathrm{B}=0.10, \mathrm{SEB}=0.03,95 \% \mathrm{CI}$ $[0.04,0.18])$. Furthermore, the degree of job autonomy was also found to be a significant determinant of self-transcendence values and innovative behavior $(\mathrm{B}=0.13, \mathrm{SEB}=0.04,95 \% \mathrm{CI}$ $[-0.21,-0.05])$. The results of this experiment confirm hypothesis H4d as well. As a result, three of the four specific mediation hypotheses have been confirmed. It can be concluded that work autonomy is a significant mediator of the relationship between employees' innovative behavior and their personal values (e.g., conservation, self-enhancement, and transcendence).

\section{CONCLUSION}

This study attempts to correlate the empirical results of ERP implementation success studies with empirically identified CSFs that appear in this line of research. In this analysis, many studies dealing with conceptual ERP implementations were largely ignored. The outcome of this research is an empirical model that is suitable for testing.

In terms of practical implications, the following are most relevant. First, a company can assess its innovation potential by understanding the relationship between individual values and attitudes toward the behaviors that are considered to be typical for innovation. In addition, this information is important to decision-making in order to determine the direction of the IT department in the future, which reflects the innovative potential of supervisory staff in specific departments. Innovativeness in management is of huge importance since IT managers are responsible for directing future business, especially IT priorities, research, and development.

Second, knowing the associations between IT managers' values and their attitudes toward innovation can help organizations, and especially IT departments, improve their innovative capacity since managers can be selected according to values that are important to them. IT managers can be evaluated with regards to their suitability for different tasks, including development, research, implementation, etc. by the human resources department. If findings are generalized to the whole population of managers, it is necessary to know which values prevent IT managers from displaying innovative behavior, since organizations can detach themselves from those values when choosing new organizational members. It is possible to evaluate this by asking a question about values during a job interview. As a result, people's behaviors are believed to reflect their attitudes.

It is possible to introduce values that support or drive typical innovative behavior into an organization's culture, thereby creating an environment that is more innovation-friendly. This contribution has the following conceptual implications. The first thing to note is that presupposed core values may not necessarily align with typical innovations. It is also shown that core values that hinder innovation or innovative behaviors or managers, which are rarely reviewed by existing literature, are equally important to this study as drivers and boosters of innovation.

The second finding was that the researchers used a variety of value dimensions to test whether there was an influence of managers' personal values on their views of typical innovative behavior and found that the impact varied depending on the dimensions used. As the selected factor for creating the attitudes of IT managers toward innovative behavior and consequently for defining their innovativeness, 
mainstream management literature focuses on their personal values.

The results can be generalized to cultures that have different cultural settings and distinct economic development paths, namely those with a long tradition of free-market economies and those that formerly transitioned. For further research, I recommend a quantitative replication and a qualitative replication using a broader definition of behavior, innovativeness, and innovation behavior. Comparison of the level of innovation displayed by IT managers with supervisory staff within other departments will also be an important part of the research.

Despite the limitations of our study, it provides empirical evidence that allows the development of new theories. Previously unstudied relationships between employees' job autonomy, personal values, and innovative behavior are revealed in the results. As a result, they offer new perspectives on innovation research, applying insights from Schwartz's (1992) theory of basic human values to a new context. Specifically, we found that individual values are capable of spurring innovation at work. This study also investigated the mediation mechanism between individual values and innovation behavior as well as the direct relationship between the two. Our study aims to answer the recent call for revealing mechanisms by which innovation is driven, which has been highly emphasized in the innovation literature. We also considered whether job autonomy could serve as a measure of context, including personal values and contextual factors. Therefore, incorporating personal values theory into job design theory can provide new insights into crucial aspects of basic human values theory.

\section{REFERENCES}

[1]. Umble, E. J., Haft, R. R., and M. M. Umble. 2003. Enterprise resource planning: Implementation procedures and critical success factors. European Journal of Operational Research, 146:2, 241-257.

[2]. M. Sumner. 2000. Risk factors in enterprisewide/ ERP projects. Journal of Information Technology, 15:4, 317-327.

[3]. Sarker, S and A. S. Lee. 2003. Using a case study to test the role of three key social enablers in ERP implementation. Information \& Management, 40:8, 813-829.

[4]. Abdinnour-Helm, S., Lengnick-Hall, M. L., and C. A. Lengnick-Hall. 2003. Pre-implementation attitudes and organizational readiness for implementing an Enterprise Resource Planning system. European Journal of Operation Research, 146:2, 258-273.

[5]. Adam, F. and P. O'Doherty. 2000. Lessons from enterprise resource planning implementations in Ireland - towards smaller and shorter ERP projects. Journal of Information Technology, 15, 305-316.

[6]. Aladwani, A. M. 2002. An integrated performance model of information systems projects. Journal of Management Information Systems, 19:1, 185-210.

[7]. Bradford, M. and J. Florin. 2003. Examining the role of innovation diffusion factors on the implementation success of enterprise resource planning systems. International Journal of Accounting Information Systems, 4, 205-225.

[8]. DeLone, W. H. and E. R. McLean. 2003. The DeLone and McLean model of information systems success: A ten-year update. Journal of Management Information Systems, 19:4, 9-30.

[9]. Francalanci, C. 2001. Predicting the implementation effort of ERP projects: Empirical evidence on SAP/R3. Journal of Information Technology, 16, 33-48. 
[10].Gefen, D. and C. M. Ridings. 2002. Implementation team responsiveness and user evaluation of customer relationship management: A quasi-experimental design study of social exchange theory. Journal of Management Information Systems, 19:1, 47-69.

[11]. Hayes, D. C., Hunton, J. E. and J. L. Reck. 2001. Market Reaction to ERP implementation announcements. Journal of Information Systems, 15:1, 3-18.

[12]. Haines, M. N. and D. L. Goodhue. 2003. Implementation partner involvement and knowledge transfer in the context of ERP implementations. International Journal of Human-Computer Interaction, 16:1, 23-38.

[13]. Ewelina Purc and Mariola Lagun. Personal Values and Innovative Behavior of Employees. Front Psychol. 2019.

[14]. Hong, K. and Y. Kim. 2002. The critical success factors for ERP implementation: An organizational fit perspective. Information \& Management, 40:1, 25-40.

[15]. Hunton, J. E., Lippincott, B. and J. L. Reck. 2003. Enterprise resource planning systems: Comparing firm performance of adopters and nonadopters. International Journal of Accounting Information Systems, 4:3, 165-184.

[16]. Hunton, J. E., McEwen, R. A. and B. Wier. 2002. The reaction of financial analysts to Enterprise Resource Planning (ERP) implementation plans. Journal of Information Systems, 16:1, 31-40.

[17]. Nah, F. F., Zuckweiler, K. M. and J. L. Lau. 2003. ERP implementation: Chief information officers' perceptions of critical success factors. International Journal of Human-Computer Interaction, 16:1, 5-22.

[18]. Newell, S., Huang, J. C., Galliers, R. D. and S. L. Pan. 2003. Implementing enterprise resource planning and knowledge management systems in tandem: Fostering efficiency and innovation complementarity. Information and Organization, $13: 1,25-52$.
[19]. Bohdanowicz, P., \& Martinac, I. (2007). Determinants and benchmarking of resource consumption in hotels-Case study of Hilton International and Scandic in Europe. Energy \& Buildings, 82-95.

[20].Zientara, P., \& Novatna, E. (2011). International hotel chains and environmental protection: An analysis of Hilton's we care programme (Europe,2006-2008). Journal of Sustainable Tourism, 797-816.

[21].Han , H., \& Hsu, J. (2010). Application of the theory of planned behavior to green hotel choice: Testing the effect of environmental friendly activities. Tourism Management, 325334.

[22]. Graci, S., \& Dodds, R. (2008). Why go green? The business case for environmental commitment in the Canadian hotel industry. An international journal of tourism \& hospitality research, 251-270.

[23]. Lee, S., \& Park, S. (2010). Do socially responsible Activities help hotels and casinos achieve their financial goals? International journal of hospitality management, 105-112.

[24]. Walker, R., \& Walker, J. (2011). Tourism Concepts \& Practices. New Delhi: Dorling Kindersley Pvt. Ltd.

[25]. Miller, M., \& Mayer, K. (2012). Importance of green hotel attributes to business and leisure travellers. Journal of Hospitality Marketing \& Management, 395-413

[26]. Judy, L., Holcomb, Randall, S., Upchurch, \& Fevzi Okumus. (2007). Corporate social responsibility: what are top hotel companies reporting? International Journal of Contemporary Hospitality Management, 461475. 